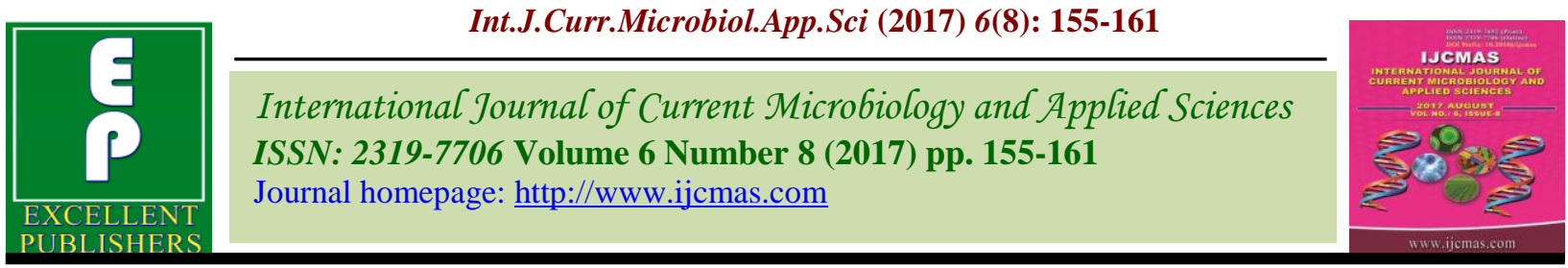

Original Research Article https://doi.org/10.20546/ijcmas.2017.608.022

\title{
Integrated Disease Management studies in Blight of Tomato
}

\author{
N. Sumalatha ${ }^{1 *}$, B. Pushpavathi ${ }^{1}$, R. Jagadeeshwar ${ }^{1}$, V. Suresh ${ }^{1}$ and R.V.S.K. Reddy ${ }^{2}$ \\ ${ }^{1}$ Department of Plant Pathology, Rice section, ARI, Rajendranagar, Acharya N G Ranga \\ Agricultural University, Hyderabad, India \\ ${ }^{2}$ Vegetable Section, YSR Horticulture University, Rajendranagar, Hyderabad 500030, India \\ *Corresponding author
}

\section{A B S T R A C T}

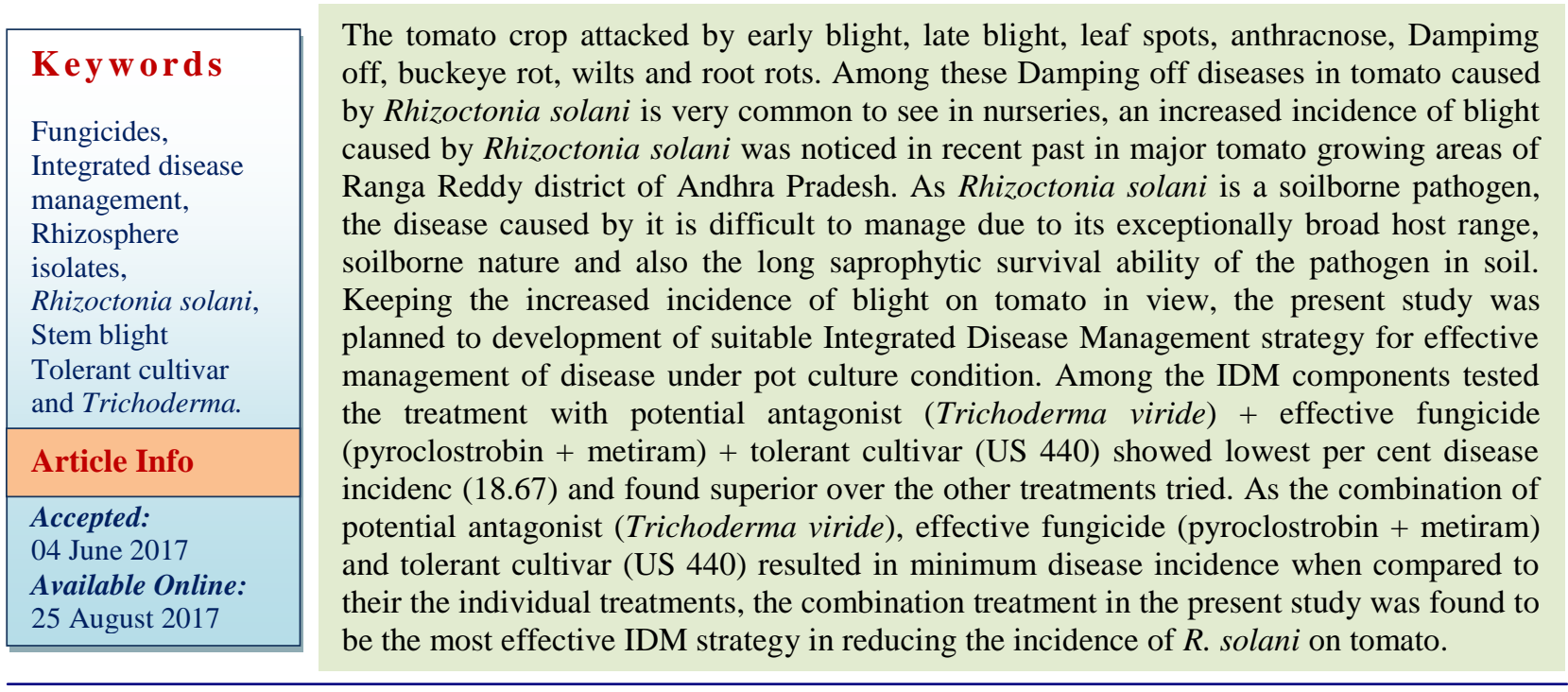

\section{Introduction}

The tomato (Solanum lycopersicum L.) is one of the most widely consumed vegetables in the world. In India, tomato is grown almost all over the country and ranks first with 0.88 million hectares of area and 18.22 million tonnes of production with a productivity of 19.50 t/ha. In Andhra Pradesh the crop is grown in 0.26 million hectares with a production and productivity of 5.21 million tones and $20 \mathrm{t} /$ ha respectively (INDIASTAT, 2013). As Rhizoctonia solani is a soilborne pathogen, the disease caused by it is difficult to manage due to its exceptionally broad host range that includes over 500 plant species including tomato. On the other hand, management of this disease is difficult not only due to its wide host range and soil borne nature but also the long saprophytic survival ability of the pathogen in soil (Kumar et al., 2011).

In tomato, in addition to root rot Rhizoctonia solani was also reported to cause stem canker (Wokoma, 2008) and damping off (Dutta and Dutta, 2007) and is considered to be the most important soil borne disease of tomato 
causing severe losses under favourable conditions at nursery beds. Apart from this the fungus was also known to cause root and crown rot incidence under greenhouse conditions (Latorre and Bernardo, 2004).

Though damping off caused by Rhizoctonia solani in tomato is very common to see in nurseries, an increased incidence of blight caused by Rhizoctonia solani was noticed in recent past in major tomato growing areas of Ranga Reddy district of Andhra Pradesh. The disease was found to appear predominantly during early transplanted to flowering and fruiting stage of the crop causing considerable loss to the crop both in terms of plant stand and yield. However, the disease incidence varied from 12.8 to $33.2 \%$ during 2011-12 rabi season under natural field conditions (Pushpavathi et al., 2013).

Keeping the increased incidence of blight on tomato in view, the present study was planned.

Development of suitable Integrated Disease Management strategy for effective management of blight in tomato caused by Rhizoctonia solani disease under pot culture condition.

\section{Materials and Methods}

Rhizoctonia solani is a soilborne pathogen, having wide host range and also the long saprophytic survival ability of the pathogen in soil. To manage blight disease a set of ten popularly grown tomato cultivars viz., PKM1, Arka meghali, Arka abha, US 440, Heemsohna, DS 800, Lyco, US 618, Bhama, 9005 Siri along with a susceptible cultivar Arka vikas were screened against $R$. solani incidence under laboratory (paper towel method) and greenhouse conditions (soil infestation and root dip inoculation methods). Of the eleven tomato cultivars screened
PKM-1 was found superior with lowest per cent disease incidence in both soil infestation (25.33) and root dip inoculation (7.50) methods US-440 was with moderate per cent disease incidence in both soil infestation (31.30) and root dip inoculation (31.25) methods.. Hence, the cultivar US-440 used for further studies as a tolerant cultivar.

The population of rhizosphere mycoflora and fluorescent pseudomonads was estimated from the soil samples collected from diseased, healthy and luxuriously growing weed plants as colony forming units (cfu) on different culture media and were tested for their antagonistic potential against $R$. solani under in vitro condition. Among the mycoflora the isolate M10 was found to be the potential antagonist and was identified as Trichoderma viride whereas the effective pseudomonad (P1) was identified as Pseudomonas fluorescens.

A set of eight fungicides (copper oxychloride, propiconazole, hexaconazole, tebuconazole, pyroclostrobin, captan+ hexaconazole, Trifloxyconazole + tebuconazole and pyroclostrobin + metiram) were evaluated at recommended, $75 \%$ of recommended, $50 \%$ of recommended, $25 \%$ of recommended dosages for their efficacy against $R$. solani by using poisoned food technique. Of these propiconazole, hexaconazole, tebuconazole, captan + hexaconazole and trifloxystrobin + tebuconazole showed cent per cent inhibition of the growth of the pathogen over control. The fungicide pyroclostrobin + metiram showed minimum inhibition (50.37) on growth of biocontrol agent Trichoderma viride at $25 \%$ of recommended dose.

Potential antagonists (Trichoderma viride), effective fungicides (pyroclostrobin + metiram), tolerant cultivar (US 440 - a cultivar with moderate PDI) and combination of these treatments were tested for their 
effectiveness on stem blight of tomato by adopting root dip inoculation method. The treatments in which host cultivar is not an integral component were imposed on the susceptible cultivar Arka vikas.

Treatments evaluated against $R$. solani to develop IDM strategy were listed here under.

While imposing the above treatments on susceptible or tolerant cultivar, the test pathogen $R$. solani was inoculated through root dip inoculation method, the potential biocontrol agent was inoculated by soil infestation method, whereas the effective fungicide was applied through soil drenching method. The treatment details are as follows:

\section{$T_{1}$ - Potential antagonist}

The effective biocontrol agent Trichoderma viride was mass multiplied on sorghum grain. The antagonist grown on sorghum grain was ground into a fine powder in a mixer- grinder and applied uniformly to the polythene bags filled with sterile soil (5 $\mathrm{kg}$ capacity). Immediately after inoculation the soil in polythene bags was sprinkled with water and was closed to raise relative humidity inside. These polythene bags were placed on a glass house bench for incubation. Two days after incubation, polythene bags were opened and observed for the presence of antagonistic mycelial mat on the soil. On the third day, the seedlings of susceptible cultivar Arka vikas subjected to root dip inoculation with mycelial suspension of $R$. solani were transplanted into these bags. Data on number of affected plants out of total number of plants was recorded.

\section{T2 - Effective fungicide}

A cultivar (US 440) with moderate PDI in screening experiment was selected as the tolerant cultivar. The seedlings of susceptible cultivar subjected to root dip inoculation with mycelial suspension of $R$. solani were applied with effective fungicide pyroclostrobin + metiram at $25 \%$ of recommended dose $(0.05 \%)$ through soil drenching method.

Data on number of affected plants out of total number of plants was recorded.

\section{T3 - Tolerant cultivar}

The seedlings of tolerant cultivar US 440 subjected to root dip inoculation with mycelial suspension of $R$. solani were transplanted in to the polythene bags filled with sterile soil and observed daily for symptom expression.

Data on number of affected plants out of total number of plants was recorded.

\section{T4 - T1 + T2 (Potential antagonist + Effective fungicide)}

The potential biocontrol agent Trichoderma viride mass multiplied on sorghum grains and ground into fine powder using a mixergrinder was added uniformly to soil filled in polythene bags (5 kg capacity) @ $50 \mathrm{~g}$ per kg soil.

These polythene bags were sprinkled with water and incubated on a greenhouse bench.

Two days after incubation, the seedlings of susceptible cultivar (Arka vikas) subjected root dip inoculation with mycelial suspension of $R$. solani were transplanted.

On the second day after transplantation, the effective fungicide pyroclostrobin + metiram at effective dose $25 \%$ of recommended dose $(0.05 \%)$ was applied through soil drenching and plants were observed daily for the presence of symptoms. Data on number of affected plants out of total number of plants was recorded. 
T5 - T1 + T3 (Potential antagonist + Tolerant cultivar)

Two days after application of potential antagonist Trichoderma viride to the soil filled in polythene bags, the seedlings of tolerant cultivar (US 440) subjected to root dip inoculation with mycelial suspension of $R$. solani were transplanted and plants were observed daily for the presence of symptoms. Data on number of affected plants out of total number of plants was recorded.

\section{$T_{6}-T_{2}+T 3$ (Effective fungicide + Tolerant cultivar)}

The seedlings of tolerant cultivar US- 440 were inoculated with $R$. solani by standard root dip technique and then two days after inoculation effective fungicide pyroclostrobin + metiram at effective dose $(0.05 \%)$ was applied to the soil. Data on number of affected plants out of total number of plants was recorded.

\section{T7 -T1 + T2 + T3 (Potential antagonist + Effective fungicide + Tolerant cultivar)}

The potential antagonist Trichoderma viride and effective fungicide pyroclostrobin + metiram at effective dose $(0.05 \%)$ were applied to soil as described in 3.8.4. Seedlings of tolerant cultivar US 440 subjected to root dip inoculation were transplanted into the Trichoderma viride inoculated soil followed by the application of fungicide. Plants were observed daily for the symptom expression. Data on number of affected plants out of total number of plants was recorded.

\section{The experiment on IDM was included with three controls}

\section{T8 - Control - 1 (Inoculated susceptible cultivar)}

Seedlings of susceptible cultivar Arka vikas subjected to root dip inoculation with mycelial suspension of $R$. solani were transplanted into the polythene bags filled with sterilized soil and observed daily for the symptom expression. Data on number of affected plants out of total number of plants was recorded.

\section{T9 - Control - 2 (Uninoculated susceptible cultivar)}

Seedlings of susceptible cultivar Arka vikas subjected to root dip inoculation with sterilized water were transplanted (without $R$. solani inoculation) into the polythene bags filled with sterilized soil and observed daily for the presence of symptoms. Data on number of affected plants out of total number of plants was recorded.

\section{T10 - Control - 3 (Uninoculated tolerant cultivar)}

Seedlings of tolerant cultivar US 440 subjected to root dip inoculation with sterilized water were transplanted into the polythene bags filled with sterilized soil and observed daily for the symptom expression. Data on number of affected plants out of total number of plants was recorded.

\section{Statistical analysis}

The data obtained from different experiments was statistically analysed using CRD and factorial CRD as per procedures suggested by Gomez and Gomez (1984). The data was transformed using Angular transformations wherever necessary and the actual percentage values along with their corresponding transformed values were given in tables (Tables 1 and 2). All the experiments in the present study were replicated thrice with suitable controls.

\section{Results and Discussion}

Potential antagonists (Trichoderma viride), effective fungicides (pyroclostrobin + 
metiram), tolerant cultivar (US 440 - a cultivar with moderate PDI) and combination of these treatments were tested for their effectiveness on stem blight of tomato by adopting root dip inoculation method. The treatments in which host cultivar is not an integral component were imposed on the susceptible cultivar Arka vikas. The data from all the treatments was recorded on seventh day after inoculation as there was no further increase in disease incidence after seven days of inoculation in case of inoculated control treatment. The data obtained is presented in table 1 and figure 1 . The results indicated that all the treatments were found to be significantly superior over control in reducing the disease incidence.

Among the treatments tried, there was no significant difference between most of the treatments for PDI. However, the treatment with potential antagonist (Trichoderma viride) + effective fungicide (pyroclostrobin + metiram) + tolerant cultivar (US 440) recorded lowest PDI (18.67) and was found to be differing significantly with all the other treatments imposed in the present study. Significantly highest per cent disease incidence (91.66) was observed in treatment with inoculated susceptible cultivar (Arka vikas), whereas the treatments with uninoculated susceptible cultivar and uninoculated tolerant cultivar showed absolutely no disease incidence. The treatment with effective fungicide showed less per cent disease incidence (31.50) when compared to treatments Trichoderma viride the potential antagonist (33.67) and US 440 the tolerant cultivar (32.00) which did not differ significantly with each other.

The treatment with combination of potential antagonist (Trichoderma viride) + effective fungicides (pyroclostrobin + metiram) showed 28.67 per cent disease incidence which was significantly superior from disease point of view over the treatments potential antagonist (Trichoderma viride) alone (33.67) and effective fungicides (pyroclostrobin + metiram) alone (31.50).

Table.1 List of treatments and their combinations evaluated against Rhizoctonia solani

\begin{tabular}{|c|c|l|}
\hline S. No. & Treatments & Combination particulars \\
\hline 1 & T1 & Potential antagonist \\
\hline 2 & T2 & Effective fungicide \\
\hline 3 & T3 & Tolerant cultivar \\
\hline 4 & T4 & T1 + T2 (Potential antagonist + Effective fungicide) \\
\hline 5 & T5 & T1 + T3 (Potential antagonist + Tolerant cultivar) \\
\hline 6 & T6 & T2 + T3 (Effective fungicide + Tolerant cultivar) \\
\hline 7 & T7 & $\begin{array}{l}\text { T1 + T2 + T3 (Potential antagonist + Effective fungicide } \\
+ \text { Tolerant cultivar) }\end{array}$ \\
\hline 8 & T8 & Control -1 (Inoculated susceptible cultivar) \\
\hline 9 & T9 & Control -2 (Uninoculated susceptible cultivar) \\
\hline 10 & T10 & Control -3 (Uninoculated tolerant cultivar) \\
\hline
\end{tabular}


Table.2 Effect of IDM components on incidence of Rhizoctonia solani in tomato

\begin{tabular}{|l|l|l|}
\hline S. No. & Treatments & Per cent Disease Incidence \\
\hline 1 & Potential antagonist (Trichoderma viride) @ 50 g per kg soil & $33.67(35.18)^{*}$ \\
\hline 2 & Effective fungicide (pyroclostrobin + metiram) @ 0.05\% & $31.50(33.61)$ \\
\hline 3 & Tolerant cultivar (US 440) & $32.00(33.92)$ \\
\hline 4 & $\begin{array}{l}\text { Potential antagonist (Trichoderma viride) @ 50 g per kg soil } \\
+ \text { Effective fungicide (pyroclostrobin + metiram) @ 0.05\% }\end{array}$ & $28.67(22.33)$ \\
\hline 5 & $\begin{array}{l}\text { Potential antagonist (Trichoderma viride) @ 50 g per kg soil } \\
+ \text { Tolerant cultivar (US 440) }\end{array}$ & $27.78(31.71)$ \\
\hline 6 & $\begin{array}{l}\text { Effective fungicide (pyroclostrobin + metiram) @ 0.05\% + } \\
\text { Tolerant cultivar (US 440) }\end{array}$ & $29.89(33.11)$ \\
\hline 7 & $\begin{array}{l}\text { Potential antagonist (Trichoderma viride) @ 50 g per kg soil } \\
+ \text { Effective fungicide (pyroclostrobin + metiram) @ 0.05\% } \\
+ \text { Tolerant cultivar (US 440) }\end{array}$ & $18.67(29.54)$ \\
\hline 8 & Control - 1 (Inoculated susceptible cultivar- Arka vikas) & $91.66(73.31)$ \\
\hline 9 & Control - 2 (Uninoculated susceptible cultivar - Arka vikas) & $0.00(0.00)$ \\
\hline 10 & Control - 3 (Uninoculated tolerant cultivar - US 440) & $0.00(0.00)$ \\
\hline $\begin{array}{l}\text { CD at 5 \% } \% \\
\text { CV \% }\end{array}$ & $\begin{array}{l}2.52 \\
0.85\end{array}$ & \\
\hline
\end{tabular}

* Figures in parentheses are angular transformed values

Fig.1 Effect of IDM components on incidence of Rhizoctonia solani in tomato

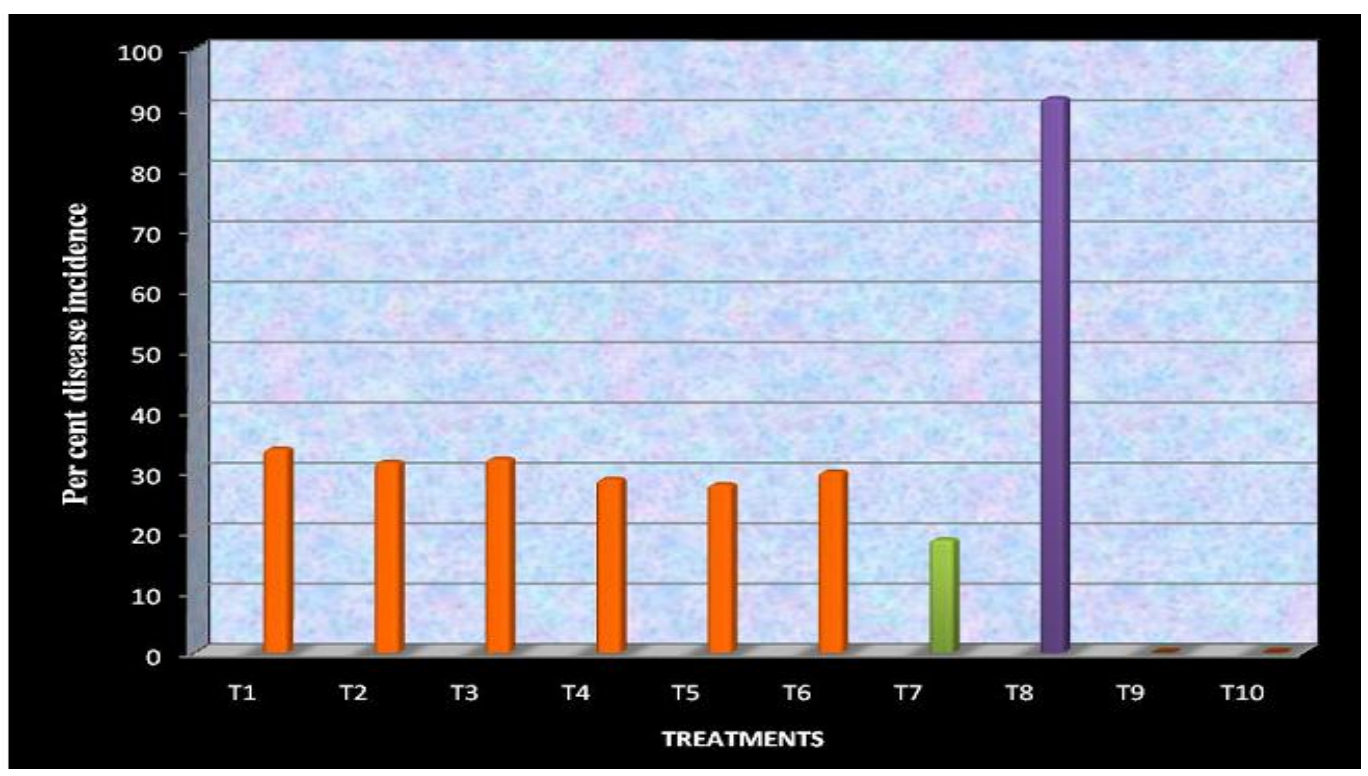

Similarly combination of potential antagonist (Trichoderma viride) + tolerant cultivar (US 440) resulted in 27.78 per cent disease incidence which was significantly superior over the potential antagonist (Trichoderma viride) alone and tolerant cultivar (US 440) alone (32.00). Though the treatment with effective fungicide (pyroclostrobin + metiram) + tolerant cultivar (US 440) showed 29.89 per cent disease incidence it was not found to be significantly effective over treatments effective fungicide (pyroclostrobin + metiram) alone and tolerant cultivar (US 440) alone. 
The combination treatment with potential antagonist (Trichoderma viride) + tolerant cultivar (US 440) also showed better results with 27.78 PDI than the treatment potential antagonist (Trichoderma viride) + effective fungicide (pyroclostrobin + metiram) with 28.67 PDI and effective fungicide (pyroclostrobin + metiram) + tolerant cultivar (US 440) with 29.89 PDI which were not significant with each other. As the PDI recorded with the treatment potential antagonist (Trichoderma viride) + effective fungicide (pyroclostrobin + metiram) + tolerant cultivar (US 440) was found to be significantly least when compared to all other treatments it is considered as the superior and potential management strategy for blight incidence on tomato. Similar results were obtained with findings of Surilirajan and Kandhari (2005), of the 16 treatments, $T$. viride (TV-3235) + Carbendazim 50WP $(0.1 \%)$ spray along with soil amendments (FYM 1\% + saw dust 1\%) showed that maximum reduction in sheath blight severity, per cent disease incidence and higher grain yield over the control.

The studies of Malathi et al., (2002) also indicated the same that the treatments receiving combination of thiophanate methyl and $P$. fluorescens recorded the maximum plant survival of $81.67 \%$ which was equal to control without pathogen. Other combined treatments also showed comparable effects without significant difference.

\section{References}

Dutta, S, and Dutta, D. 2007. Evaluation of biocontrol potentiality of native plant growth promoting bacteria against Rhizoctonia solani mediated damping off disease of tomato. J. Mycopathol. Res., 45(2): 201-206.

Gomez, K.A., and Gomez, A.A. 1984. Statistical Procedures for Agricultural Research. Second edition, John Willey and Sons, New York. Pp. 316-356.

INDIASTAT. 2013. Crop statistics in India. www.indiastat.com.

Kumar, V., Haseeb, H., and Khan, R.U. 2011. Comparative efficacy of bioinoculents, organic amendments and pesticides against Rhizoctonia solani alone on tomato CV. K-25 under Pot Conditions. World J. Agricult. Sci., 7(6): 648-652.

Latorre and Bernardo. 2004. Enfermedades de las plantas cultivades. Santilago. Ediciones Universidad catolica de chile. Pp. 638.

Malathi, P., Viswanathan, R., Padmanaban, P., Mohanraj, D., and Sunder, A.R. 2002. Compatibility of biocontrol agents with fungicides against red rot disease of sugarcane. Sugar Tech., 4 (3\&4): $131-136$.

Pushapavathi, B., Sireesha, K., Reddy, P.N. and Rajender, J. 2013. Prevalence of Rhizoctonia solani blight of tomato in Ranga Reddy District of Andhra Pradesh. 35 ${ }^{\text {th }}$ Annual conference and National symposium on "Innovative and Ecofriendly Research Approch for Plant Disease Management" DP-26.

Surilirajan, M., and Kandhari, J. 2005. Integrated management of rice sheath blight under field condition. Indian Phytopathol., 58(4): 431-436.

\section{How to cite this article:}

Sumalatha, N., B. Pushpavathi, R. Jagadeeshwar, V. Suresh and Reddy, R.V.S.K. 2017. Integrated Disease Management studies in Blight of Tomato. Int.J.Curr.Microbiol.App.Sci. 6(8): 155-161. doi: https://doi.org/10.20546/ijcmas.2017.608.022 